\title{
COVID-19 and cardiovascular complications - preliminary results of the LATE-COVID study
}

Joanna Lewek ${ }^{1,2}$, Izabela Jatczak-Pawlik ${ }^{1,3}$, Marek Maciejewski ${ }^{2}$, Piotr Jankowski ${ }^{3}$, Maciej Banach ${ }^{1,3,4}$

${ }^{1}$ Department of Hypertension, Chair of Nephrology and Hypertension,
Medical University of Lodz, Poland
2Department of Cardiology and Adult Congenital Heart Diseases, Polish Mother's
Memorial Hospital Research Institute (PMMHRI), Lodz, Poland
3Polish Mother's Memorial Hospital Research Institute (PMMHRI), Lodz, Poland
${ }^{4}$ Cardiovascular Research Centre, University of Zielona Gora, Zielona Gora, Poland

Submitted: 3 March 2021; Accepted: 11 March 2021;

Online publication: 18 March 2021

Arch Med Sci 2021; 17 (3): 818-822

DOI: https://doi.org/10.5114/aoms/134211

Copyright @ 2021 Termedia \& Banach

\section{Abstract}

Introduction: Coronavirus disease 2019 (COVID-19) may affect many organs and may be responsible for numerous complications including cardiovascular problems.

Methods: We analysed consecutive patients $(n=51)$ admitted to the cardiology department between $1^{\text {st }}$ October 2020 and $31^{\text {st }}$ January 2021 due to symptoms which might have reflected cardiovascular complications following COVID-19. We collected data concerning clinical characteristics, results of laboratory tests, echocardiography and 24-hour ambulatory ECG recording. Results: The post-COVID-19 complications appeared 1-4 months after disease recovery. Severe cardiovascular complications were observed in $27.5 \%$ of hospitalized patients. In comparison to those with mild complications, patients with severe complications had significantly higher prevalence of diabetes ( 36 vs. $8 \% ; p=0.01$ ), decrease in ejection fraction ( $36 \%$ vs. $0 \%$, $p<0.001$ ), higher resting heart rate at admission ( 85 vs. 72 bpm; $p<0.001$ ), and higher levels of C-reactive protein $(p=0.02)$ and troponin T (17.9 vs. $4.2 \mathrm{pg} / \mathrm{ml} ; p=0.01)$. Dyspnoea and exercise intolerance were also more frequent in patients with severe complications.

Conclusions: Diabetes, elevated level of CRP and troponin, heart rate variability parameters and worsening of left ventricular ejection fraction are related to the severity of cardiovascular complications following COVID-19 infection.

Key words: COVID-19, cardiovascular complications, myocarditis, decrease in left ventricular ejection fraction, autonomic dysregulation.

Coronavirus disease 2019 (COVID-19) is an infectious disease caused by severe acute respiratory syndrome coronavirus 2 (SARS-CoV-2) [1]. A wide range of cardiovascular complications has been linked to COVID-19 [2]. It is well known that COVID-19 affects the heart. The possible pathophysiology includes dysregulation of the renin-angiotensin-aldosterone system, destabilization of plaques, cytokine release syndrome, and disorders of coagulation processes [3-5]. Long-term complications in patients who had mild symptoms during the acute phase of infection, not requiring hospitalization, oxygen therapy or mechanical ventilation, have not been fully studied.

\author{
Corresponding authors: \\ Joanna Lewek MD, PhD \\ Medical University of Lodz \\ 281/289 Rzgowska St \\ 93-338 Lodz, Poland \\ Phone: +48 422711593 \\ E-mail: joanna.lewek@umed. \\ lodz.pl
}

Prof. Maciej Banach MD, PhD, FNLA, FAHA, FESC, FASA Medical University of Lodz 281/289 Rzgowska St 93-338 Lodz, Poland Phone: +48 422711179 Fax: +48 422711560 E-mail: maciej.banach@ icloud.com 
Therefore, our aim was to assess factors related to the severity of post-COVID complications among patients without severe symptoms in the acute phase of COVID-19.

Methods. The study included consecutive COVID-19 convalescents (coronavirus infection was confirmed with a real-time polymerase chain reaction test) admitted to the Department of Cardiology and Adult Congenital Heart Diseases of the Polish Mother's Memorial Research Institute (PMMHRI) in Lodz, Poland, for cardiovascular complications. Patients were hospitalized between $1^{\text {st }}$ October 2020 and $31^{\text {st }}$ January 2021. The patients underwent laboratory testing, echocardiography, and 24-hour ECG monitoring. We defined severe complications as: myocarditis, pulmonary embolism, angina pectoris requiring myocardial revascularization, a decrease in left ventricular ejection fraction from the pre-disease value greater than $10 \%$, the onset of atrial fibrillation or supraventricular tachycardia, or thrombi within the heart cavities. Some of the patients presented more than one of the complications listed above.

Statistical analysis. Normal distribution was assessed using the Shapiro-Wilk test. The obtained results were presented as mean \pm standard deviation or median $\left(25^{\text {th }}-75^{\text {th }}\right.$ percentile) for continuous variables, as appropriate, and as proportions in the case of categorical variables. Comparisons between groups were performed using Student's $t$-test for independent variables and the Mann-Whitney $U$ test or $\chi^{2}$ test with Yates's correction, as appropriate. The generalised linear model was used to calculate $p$ adjusted for sex and age. For all calculations $p$-values $<0.05$ were considered statistically significant. Statistical analysis was performed using the software Statistica v.13 (TIBCO Software Inc., Palo Alto, CA, USA).

Results. Finally, we studied 51 consecutive patients (mean age: $53 \pm 16$ years, 27 males and 24 females) hospitalized 2 months after COVID-19 on average (median 2; standard deviation 1-2 months). Symptoms reported by the patients at admission included dyspnoea at rest in 5 (10\%) patients, deterioration of exercise tolerance in 26 (51\%), chest pain in $13(25 \%)$, increased blood pressure in 7 (14\%), palpitations in $9(18 \%)$, cognitive dysfunction in $3(6 \%)$, weakness in $5(10 \%)$ and oedema in 2 (4\%). Overall, $53 \%$ of patients were previously prescribed $\beta$-blockers, angiotensin converting enzyme inhibitors (ACEI) (22\%), sartans (22\%), anticoagulants (25\%) and $27 \%$ statins. Out of 51 analysed patients, myocarditis was diagnosed in 2 (4\%) patients, pulmonary embolism in 1 (2\%) patient, angina pectoris requiring myocardial revascularization in 4 (8\%) patients, a decrease in left ventricular ejection fraction (LVEF) from the pre-disease value greater than $10 \%$ in $5(10 \%)$ patients, the onset of atrial fibrillation (AF) or supraventricular tachycardia in $5(10 \%)$ patients, and thrombi within the heart cavities in 1 (2\%) patient.

Overall, severe complications were diagnosed in 14 of the 51 patients (27.5\%). Dyspnoea and exercise intolerance were more frequent in patients with severe complications (Table I). The prevalence of other symptoms was similar between groups. There were no statistically significant differences in age, sex, body mass index, and blood pressure between groups. On the other hand, the presence of severe post-COVID-19 complications was significantly associated with a previous history of type 2 diabetes (DMt2). Patients with severe complications had higher $\mathrm{C}$-reactive protein (CRP) (1.65 vs. 0.62, $p=0.02$ ) and troponin T level (17.9 vs. $4.2 \mathrm{pg} / \mathrm{ml} ; p=0.01$ ) (Table II). In comparison to those with mild complications, patients with severe complications also had significantly more often a decrease in ejection fraction $(36 \%$ vs. $0 \%, p<0.001)$, and higher resting heart rate at admission (85 vs. $72 \mathrm{bpm} ; p<0.001$ ). We did not observe statistically significant differences in the usage of $\beta$-blockers, ACEI, sartans and statins between the groups. Patients with severe complications were more frequently prescribed anticoagulants (50\% vs. $16 \%, p=0.02)$.

Discussion. To the best of our knowledge, this is one of the first real-life analyses on the prevalence and risk factors of severe cardiovascular complications in COVID-19 convalescents who were without severe symptoms in the acute phase of COVID-19. High CRP and troponin levels, history of diabetes, reduced LVEF, high resting heart rate and dyspnoea and exercise intolerance at admission were more prevalent in patients with severe cardiovascular complications, and might be used as simple indicators of the risk of late severe cardiovascular complications of COVID-19. However, due to the cross-sectional design of the study we cannot make any direct conclusions about the causality of the associations. Nevertheless, our results may help with the preliminary assessment, predicting the possibility of a severe cardiovascular disease underlying the symptoms in postCOVID-19 convalescent patients hospitalized for their symptoms, which may indicate a new cardiovascular disease. Higher prevalence of diabetes in patients with severe complications is consistent with the previous evidence $[6,7]$. Our data confirmed that the presence of DMt2 affects not only the acute phase of the disease but also the long-term complications. Moreover, we observed significant differences in parameters of frequency domain analysis of heart rate variability. It is possible that the observed differences are signs of disturbances in the function of the autonomic 
Table I. Clinical characteristics, symptoms and comorbidities of patients with severe and mild complications after COVID-19

\begin{tabular}{|c|c|c|c|c|c|}
\hline Variable & $\begin{array}{c}\text { Severe } \\
\text { complications }\end{array}$ & $\begin{array}{c}\text { Mild } \\
\text { complications }\end{array}$ & $P$-value & $\begin{array}{c}P \text { adjusted } \\
\text { (sex and } \\
\text { age) }\end{array}$ & Total \\
\hline \multicolumn{6}{|l|}{ Characteristics of studied population $(n=51)$ : } \\
\hline Age [years] & $59 \pm 17$ & $51 \pm 16$ & 0.12 & & $53 \pm 16$ \\
\hline Males & $9(64 \%)$ & $18(49 \%)$ & 0.33 & & $27(53 \%)$ \\
\hline Time since onset of the disease [months] & $2(2-3)$ & $2(1-2)$ & 0.14 & 0.14 & $2(1-3)$ \\
\hline Weight $[\mathrm{kg}]$ & $84 \pm 19$ & $76 \pm 16$ & 0.19 & 0.14 & $78 \pm 17$ \\
\hline Height $[\mathrm{cm}]$ & $172 \pm 8$ & $169 \pm 8$ & 0.34 & 0.14 & $170 \pm 8$ \\
\hline Body mass index $\left[\mathrm{kg} / \mathrm{m}^{2}\right]$ & $27 \pm 6$ & $26 \pm 4$ & 0.46 & 0.37 & $26 \pm 4$ \\
\hline Systolic blood pressure [mm Hg] & $137(125-147)$ & $130(125-141)$ & 0.61 & 0.60 & $131(125-147)$ \\
\hline Diastolic blood pressure [mm Hg] & $81(79-90)$ & $81(74-91)$ & 0.75 & 0.47 & $81(74-91)$ \\
\hline Resting heart rate at admission [bpm] & $85(76-96)$ & $72(70-78)$ & 0.0007 & 0.0005 & $75(70-80)$ \\
\hline Never-smokers & $7(50 \%)$ & $25(68 \%)$ & 0.32 & 0.50 & $32(63 \%)$ \\
\hline \multicolumn{6}{|l|}{ Previously prescribed drugs $(n=51)$ : } \\
\hline$\beta$-blockers & $9(64 \%)$ & $18(49 \%)$ & 0.33 & 0.36 & $27(53 \%)$ \\
\hline ACEI & $3(21 \%)$ & $8(22 \%)$ & 1.00 & 0.99 & $11(22 \%)$ \\
\hline Sartans & $2(14 \%)$ & $9(24 \%)$ & 0.45 & 0.51 & $11(22 \%)$ \\
\hline Statins & $6(43 \%)$ & $8(22 \%)$ & 0.14 & 0.19 & $14(27 \%)$ \\
\hline Anticoagulants & $7(50 \%)$ & $6(16 \%)$ & 0.02 & 0.02 & $13(25 \%)$ \\
\hline \multicolumn{6}{|l|}{ Symptoms at admission $(n=51)$ : } \\
\hline Dyspnoea at rest & $4(29 \%)$ & $1(3 \%)$ & 0.006 & 0.01 & 5 \\
\hline Deterioration of exercise tolerance & $12(86 \%)$ & $14(38 \%)$ & 0.003 & 0.009 & $26(51 \%)$ \\
\hline Chest pain & $3(21 \%)$ & $10(27 \%)$ & 0.70 & 0.74 & $13(25 \%)$ \\
\hline Increased blood pressure & $1(7 \%)$ & $6(16 \%)$ & 0.42 & 0.50 & $7(14 \%)$ \\
\hline Palpitations & $3(21 \%)$ & $6(16 \%)$ & 0.68 & 0.72 & $9(18 \%)$ \\
\hline Cognitive dysfunction & $1(7 \%)$ & $2(5 \%)$ & 0.84 & 0.85 & $3(6 \%)$ \\
\hline Headache & $0(0 \%)$ & $1(3 \%)$ & 0.57 & 0.59 & $1(2 \%)$ \\
\hline Muscle pain & $0(0 \%)$ & $1(3 \%)$ & 0.57 & 0.62 & $1(2 \%)$ \\
\hline Weakness & $2(14 \%)$ & $3(8 \%)$ & 0.53 & 0.59 & $5(10 \%)$ \\
\hline Lower limb oedema & $1(7 \%)$ & $1(3 \%)$ & 0.49 & 0.56 & $2(4 \%)$ \\
\hline \multicolumn{6}{|l|}{ Comorbidities $(n=51)$ : } \\
\hline Chronic coronary syndrome & $3(21 \%)$ & $5(14 \%)$ & 0.50 & 0.54 & $8(16 \%)$ \\
\hline Stroke in the history & $0(0 \%)$ & $2(5 \%)$ & 0.40 & 0.47 & $2(4 \%)$ \\
\hline Heart failure & $3(21 \%)$ & $3(8 \%)$ & 0.20 & 0.27 & $6(12 \%)$ \\
\hline Hypertension & $7(50 \%)$ & $12(32 \%)$ & 0.26 & 0.30 & $19(37 \%)$ \\
\hline Cancer & $1(7 \%)$ & $7(19 \%)$ & 0.31 & 0.40 & $8(16 \%)$ \\
\hline Lung diseases & $0(0 \%)$ & $1(3 \%)$ & 0.57 & 0.62 & $1(2 \%)$ \\
\hline Diabetes mellitus & $5(36 \%)$ & $3(8 \%)$ & 0.01 & 0.04 & $8(16 \%)$ \\
\hline Atrial fibrillation & $4(29 \%)$ & $6(16 \%)$ & 0.33 & 0.31 & $10(20 \%)$ \\
\hline Arrhythmias & $0(0 \%)$ & $3(8 \%)$ & 0.29 & 0.38 & $3(6 \%)$ \\
\hline Congenital heart disease & $2(14 \%)$ & $8(22 \%)$ & 0.57 & 0.63 & $10(20 \%)$ \\
\hline Thyroid disorders & $2(14 \%)$ & $4(11 \%)$ & 0.75 & 0.77 & $6(12 \%)$ \\
\hline No comorbidities & $3(21 \%)$ & $12(32 \%)$ & 0.45 & 0.51 & $15(29 \%)$ \\
\hline
\end{tabular}

$A C E I$ - angiotensin converting enzyme inhibitors, bpm - beats per minute. 
Table II. Comparison of laboratory test results, echocardiography, and 24-hour ambulatory ECG monitoring between patients with severe and mild complications after COVID-19

\begin{tabular}{|c|c|c|c|c|c|}
\hline Variable & $\begin{array}{c}\text { Severe } \\
\text { complications }\end{array}$ & $\begin{array}{c}\text { Mild } \\
\text { complications }\end{array}$ & $P$-value & $\begin{array}{c}P \text { adjusted } \\
\text { (sex and } \\
\text { age) }\end{array}$ & Total \\
\hline \multicolumn{6}{|l|}{ Laboratory test results: } \\
\hline White blood count $\left[\times 10^{3} / \mu l\right](n=51)$ & $5.69(4.82-6.37)$ & $5.81(4.86-6.83)$ & 0.84 & 0.42 & $5.7(4.82-6.83)$ \\
\hline Red blood count $\left[\times 10^{6} / \mu \mathrm{l}\right](n=51)$ & $4.24 \pm 0.51$ & $4.44 \pm 0.62$ & 0.28 & 0.28 & $4.39 \pm 0.59$ \\
\hline Haemoglobin [g/dl] $(n=51)$ & $12.84 \pm 1.78$ & $13.31 \pm 1.68$ & 0.39 & 0.38 & $13.18 \pm 1.71$ \\
\hline Platelet count $\left[\times 10^{3} / \mu \mathrm{l}\right](n=51)$ & $190.43 \pm 50.28$ & $201.59 \pm 54.80$ & 0.51 & 0.55 & $198.53 \pm 53.34$ \\
\hline Urea $[\mathrm{mg} / \mathrm{dl}](n=51)$ & $35(32-38)$ & $31(25-39)$ & 0.39 & 0.95 & $34(27-39)$ \\
\hline AspAT [U/I] $(n=51)$ & $28.5(24-38)$ & $26(24-31)$ & 0.34 & 0.15 & $27(24-33)$ \\
\hline AIAT [U/I] $(n=51)$ & $23(15-33)$ & $21(15-25)$ & 0.51 & 0.17 & $21(15-28)$ \\
\hline C-reactive protein $(\mathrm{CRP})[\mathrm{mg} / \mathrm{dl}](n=51)$ & $0.5(0.5-4)$ & $0.5(0.5-0.5)$ & 0.02 & 0.02 & $0.5(0.5-0.5)$ \\
\hline D-dimer [ng/ml] $(n=43)$ & $260.5(169-376)$ & $266(171-354)$ & 0.99 & 0.78 & $266(171-354)$ \\
\hline Creatinine $[\mathrm{mg} / \mathrm{dl}](n=51)$ & $0.81(0.68-0.97)$ & $0.79(0.65-0.90)$ & 0.45 & 0.42 & $0.79(0.66-0.92)$ \\
\hline $\begin{array}{l}\text { Glomerular filtration rate } \\
{\left[\mathrm{ml} / \mathrm{min} / 1.73 \mathrm{~m}^{2}\right](n=51)}\end{array}$ & $88.35 \pm 26.25$ & $92.56 \pm 23.38$ & 0.58 & 0.50 & $91.41 \pm 24.01$ \\
\hline NT-proBNP [pg/ml] $(n=43)$ & $666(134-1359)$ & $78(36-594)$ & 0.04 & 0.88 & $123(47-1032)$ \\
\hline Total cholesterol $[\mathrm{mg} / \mathrm{dl}](n=51)$ & $148.07 \pm 40.07$ & $168.84 \pm 42.01$ & 0.12 & 0.16 & $163.14 \pm 42.14$ \\
\hline $\begin{array}{l}\text { Low-density lipoprotein cholesterol } \\
{[\mathrm{mg} / \mathrm{dl}](n=51)}\end{array}$ & $78.71 \pm 36.76$ & $93.78 \pm 36.20$ & 0.19 & 0.27 & $89.65 \pm 36.62$ \\
\hline $\begin{array}{l}\text { High-density lipoprotein cholesterol } \\
{[\mathrm{mg} / \mathrm{dl}](n=51)}\end{array}$ & $49.43 \pm 16.09$ & $51.57 \pm 15.87$ & 0.67 & 0.69 & $50.98 \pm 15.8$ \\
\hline Triglycerides [mg/dl] $(n=51)$ & $126.5(62-167)$ & $89(75-129)$ & 0.20 & 0.07 & $98(74-139)$ \\
\hline $\mathrm{TSH}[\mu \mathrm{lU} / \mathrm{ml}](n=51)$ & $1.82 \pm 1.09$ & $1.85 \pm 0.88$ & 0.91 & 0.93 & $1.84 \pm 0.93$ \\
\hline Troponin T [pg/ml] $(\mathrm{TnT})(n=48)$ & $17.9(7.9-39.2)$ & $4.2(3-11.6)$ & 0.003 & 0.01 & $6.35(3-19)$ \\
\hline \multicolumn{6}{|l|}{ Echocardiography $(n=51)$ : } \\
\hline Left atrial volume index $\left[\mathrm{ml} / \mathrm{m}^{2}\right]$ & $33.85(27.3-44)$ & $33.9(26-52)$ & 0.91 & 0.59 & $33.9(26.4-46.9)$ \\
\hline Right atrial area $\left[\mathrm{cm}^{2}\right]$ & $18.4(14.6-21.3)$ & $15.4(13-20.6)$ & 0.41 & 0.94 & $16.2(13-20.65)$ \\
\hline $\begin{array}{l}\text { Left ventricular end-diastolic volume } \\
\text { (LVEDV) [ml] }\end{array}$ & $89(72-102)$ & $91.5(63-107)$ & 0.82 & 0.70 & $91(64-105)$ \\
\hline $\begin{array}{l}\text { Left ventricular end-systolic volume } \\
\text { (LVESV) [ml] }\end{array}$ & $44(28-50)$ & $35(23-44)$ & 0.26 & 0.87 & $36(24-49)$ \\
\hline Left ventricular ejection fraction (\%) & $53(45-59)$ & $63(57-66)$ & 0.005 & 0.06 & $62(53-66)$ \\
\hline Decrease in ejection fraction (\%) & $5(36 \%)$ & $0(0 \%)$ & 0.0002 & 0.0009 & $5(10 \%)$ \\
\hline $\begin{array}{l}\text { Tricuspid annulus movement (TAM) } \\
\text { [mm] }\end{array}$ & $20(19-21)$ & $24(21-26)$ & 0.01 & 0.08 & $23(20-25)$ \\
\hline$S^{\prime}$ & $12.5(12-15)$ & $14(12-15)$ & 0.51 & 0.53 & $13.5(12-15)$ \\
\hline Diastolic dysfunction & $6(43 \%)$ & $8(22 \%)$ & 0.28 & 0.25 & $14(27 \%)$ \\
\hline Global longitudinal strain (\%) & $\begin{array}{c}-17.75 \\
(-18.8--14) \\
\end{array}$ & $\begin{array}{c}-20.5 \\
(-21.1--19.5)\end{array}$ & 0.02 & 0.18 & $\begin{array}{c}-19.7 \\
(-21.1--18.5) \\
\end{array}$ \\
\hline \multicolumn{6}{|l|}{ 24-h ambulatory ECG monitoring $(n=49)$ : } \\
\hline Minimum HR [bpm] $(n=49)$ & $54 \pm 11$ & $53 \pm 7$ & 0.65 & 0.71 & $53 \pm 8$ \\
\hline Maximum HR (bpm) $(n=49)$ & $100 \pm 11$ & $105 \pm 15$ & 0.25 & 0.31 & $104 \pm 14$ \\
\hline Mean HR [bpm] $(n=49)$ & $71 \pm 9$ & $69 \pm 7$ & 0.51 & 0.59 & $70 \pm 8$ \\
\hline Ventricular premature beats $(n=49)$ & $3(2-96)$ & $3(0-31)$ & 0.51 & 0.49 & $3(0-42)$ \\
\hline $\begin{array}{l}\text { Supraventricular premature beats } \\
(n=49)\end{array}$ & $20(3-354)$ & $8(1-35)$ & 0.31 & 0.12 & $10(1-45)$ \\
\hline SDNN [ms] $(n=46)$ & $127.17 \pm 53.77$ & $137.76 \pm 41.43$ & 0.49 & 0.57 & $135.00 \pm 44.58$ \\
\hline SDANN [ms] $(n=46)$ & $90.42 \pm 46.48$ & $101.65 \pm 34.42$ & 0.38 & 0.47 & $98.72 \pm 37.71$ \\
\hline
\end{tabular}


Table II. Cont.

\begin{tabular}{|c|c|c|c|c|c|}
\hline Variable & $\begin{array}{c}\text { Severe } \\
\text { complications }\end{array}$ & $\begin{array}{c}\text { Mild } \\
\text { complications }\end{array}$ & $P$-value & $\begin{array}{c}P \text { adjusted } \\
\text { (sex and } \\
\text { age) }\end{array}$ & Total \\
\hline Triangular index (HRV TI) $(n=46)$ & $24.67 \pm 10.95$ & $28.71 \pm 10.03$ & 0.25 & 0.35 & $27.65 \pm 10.30$ \\
\hline $\begin{array}{l}\text { Root mean square of successive } \\
\text { differences [ms] }(n=46)\end{array}$ & $61(43-95)$ & $43(37-65)$ & 0.18 & 0.85 & $46(37-77)$ \\
\hline LF/HF $(n=46)$ & $1.55(0.73-3.19)$ & $4.12(1.51-6.37)$ & 0.03 & 0.86 & $3.37(1.177-5.05)$ \\
\hline LF norm $(n=46)$ & $\begin{array}{c}53.62 \\
(33.15-66.68)\end{array}$ & $\begin{array}{c}77.87 \\
(57.55-84.59)\end{array}$ & 0.02 & 0.03 & $\begin{array}{c}72.79 \\
(51.25-80.16)\end{array}$ \\
\hline HF norm $(n=46)$ & $\begin{array}{c}35.8 \\
(22.94-46.76)\end{array}$ & $\begin{array}{c}19.17 \\
(13.34-38.04)\end{array}$ & 0.04 & 0.04 & $\begin{array}{c}21.71 \\
(15.68-41.67)\end{array}$ \\
\hline
\end{tabular}

NT-proBNP - N-terminal pro brain natriuretic peptide, SDNN - standard deviation of NN intervals, SDANN - standard deviation of average $N N$ intervals, LF - low frequency, HF - high frequency.

nervous system [8]. High CRP and troponin levels were also previously observed as a biomarker of severe complications but mainly in the acute phase of the COVID-19 disease $[9,10]$. Our preliminary report has some obvious limitations, mainly associated with the relatively low number of patients, especially those with severe complications, that prevent us from drawing direct conclusions and do not allow us to prove a causal relationship between the measured variables and severe complications. We are continuing the LATE complications after COVID-19 (LATE-COVID) study in order to validate these results.

In conclusion, we found a significant association between severity of cardiovascular complications following COVID-19 infection and the presence of diabetes, elevated CRP and troponin T levels, reduction of LVEF, and impaired parameters of heart rate variability.

\section{Conflict of interest}

The authors declare no conflict of interest.

\section{References}

1. Katsiki N, Banach M, Mikhailidis DP. Lipid-lowering therapy and renin-angiotensin-aldosterone system inhibitors in the era of the COVID-19 pandemic. Arch Med Sci 2020; 16: 485-9.

2. Long B, Brady W, Koyfman A, Gottlieb M. Cardiovascular complications in COVID-19. Am J Emerg Med 2020; 38: 504-7.

3. Petrovic V, Radenkovic D, Radenkovic G, Djordjevic V, Banach M. Pathophysiology of cardiovascular complications in COVID-19. Front Physiol 2020; 11: 575600.

4. Bhaskar S, Sinha A, Banach M, et al. Cytokine storm in COVID-19 - immunopathological mechanisms, clinical considerations, and therapeutic approaches: the REPROGRAM Consortium Position Paper 2020; 11: 1648.

5. Radenkovic D, Chawla S, Pirro M, Sahebkar A, Banach M. Cholesterol in Relation to COVID-19: should we care about it? J Clin Med 2020; 9: 1909.

6. Li B, Yang J, Zhao F, et al. Prevalence and impact of cardiovascular metabolic diseases on COVID-19 in China. Clin Res Cardiol 2020; 109: 531-8.
7. Huang I, Lim MA, Pranata R. Diabetes mellitus is associated with increased mortality and severity of disease in COVID-19 pneumonia - a systematic review, meta-analysis, and meta-regression. Diabetes Metab Syndr 2020; 14: 395-403.

8. Heart rate variability. Standards of measurement, physiological interpretation, and clinical use. Task Force of the European Society of Cardiology and the North American Society of Pacing and Electrophysiology. Eur Heart J 1996; 17: 354-81.

9. Parsamanesh N, Karami-Zarandi M, Banach M, Penson PE, Sahebkar A. Effects of statins on myocarditis: a review of underlying molecular mechanisms. Prog Cardiovasc Dis 2021; doi: 10.1016/j.pcad.2021.02.008.

10. Wibowo A, Pranata R, Akbar MR, Purnomowati A, Martha JW. The prognostic performance of troponin in COVID-19: a diagnostic meta-analysis and meta-regression. Int J Infect Dis 2021; 105: 312-8. 